\title{
Fetal programming of insulin-like growth factor (IGF)-I and IGF-binding protein-3: evidence for an altered response to undernutrition in late gestation following exposure to periconceptual undernutrition in the sheep
}

\author{
B W Gallaher, B H Breier, C L Keven, J E Harding and \\ P D Gluckman
}

Research Centre for Developmental Medicine and Biology, Faculty of Medicine and Health Science, University of Auckland, Auckland, New Zealand

(Requests for offprints should be addressed to B H Breier, Research Centre for Developmental Medicine and Biology, Faculty of Medicine and Health Science, University of Auckland, Private Bag 92019, Auckland, New Zealand)

\begin{abstract}
It has been demonstrated in several animal models that undernutrition in utero has significant long lasting effects on subsequent fetal and postnatal development. To address the hypothesis that the insulin-like growth factors (IGFs) may mediate such effects, our study examined whether a period of periconceptual maternal undernutrition could have a lasting influence on the IGF axis in the fetal sheep. Ewes were either allowed to feed ad libitum or kept undernourished from day 60 prior to mating until day 30 after conception, and then both groups were allowed to feed ad libitum. These groups were further divided at day 105 of gestation, either being fed ad libitum or undernourished until day 115 of gestation. Fetal and maternal blood samples were obtained at both day 105 and 115 of gestation. We describe the development of a specific homologous RIA to measure ovine IGF-binding protein-3 (IGFBP-3) in fetal and maternal sheep plasma. Fetal plasma IGFBP-3 and
\end{abstract}

IGF-I concentrations were significantly $(P<0 \cdot 05)$ reduced at day 115 of gestation after maternal undernutrition. The fetal plasma IGFBP-2 levels were unchanged. The degree of reduction in fetal plasma IGFBP-3 and IGF-I between day 105 and 115 of gestation as a response to acute maternal undernutrition was significantly greater $(P<0.05)$ in fetuses of mothers receiving low periconceptual nutrition. The response of maternal plasma IGFBP-3 and IGF-I to undernutrition did not depend on the level of periconceptual nutrition. Western blot data indicate that changes in either maternal or fetal plasma IGFBP-3 concentrations were not the result of increased proteolytic activity. These results suggest that exposure to maternal periconceptual undernutrition reprograms IGFBP-3 and IGF-I regulation in the developing sheep fetus, altering its response to undernutrition in late gestation.

Journal of Endocrinology (1998) 159, 501-508

\section{Introduction}

Fetal growth and development is limited both by the intrauterine environment (e.g. nutrient uptake by the placenta and its availability to the fetus) and by the genetic potential. In the sheep, inadequate nutrient supply to the fetus (Mellor \& Matheson 1979, Owens et al. 1987) leads to fetal growth retardation. While some consequences of fetal undernutrition are transitory, others are observable even into adulthood. For example, undernutrition in utero leads to elevated blood pressure in adult guinea pigs (Persson \& Jansson 1992) and rats (Woodall et al. 1996b). In humans, poor fetal growth as reflected by factors such as low birthweight, low fetal/placental weight ratio or a reduced neonatal growth rate is associated with an increased risk of developing adult pathophysiologies such as cardiovascular disease and non insulin-dependent diabetes mellitus (Barker 1997). Such permanent alterations of developmental and homeostatic processes have been termed 'fetal reprogramming' (Barker et al. 1995).

It has long been suggested that insulin-like growth factor (IGF)-I may play a key role during fetal growth (for a review see Gluckman 1995), since a number of studies report a close association between birth weight and plasma concentrations of IGF-I. However, the physiologic mechanisms which link fetal growth retardation with adult sequelae have not yet been defined, although alterations in endocrine pathways such as the IGF/IGF-binding protein (IGFBP) axis have been implicated (Barker et al. 1993, Woodall et al. 1997). The role of IGFs in embryonic and fetal development (Baker et al. 1993, Han et al. 1994) and the sensitivity of IGFs to acute changes in nutritional status have been well defined (Strauss et al. 1991, Osborn et al. 1992, Gallaher et al. 1994). 
Harding \& Johnston (1995) and Harding (1997) demonstrated that sheep fetuses growing slowly in late gestation did not further slow their growth rate when subjected to 10 days of severe maternal undernutrition. It was proposed that these fetuses, as a result of exposure to periconceptual undernutrition, had adapted to reduced nutrient supply which subsequently allowed them to continue growth during later periods of maternal undernutrition. We have reported in a preliminary communication (Gallaher et al. 1995b) that fetal plasma levels of glucose and insulin are markedly reduced as an acute response to undernutrition in late gestation without any long-term effects of periconceptional undernutrition. However, periconceptual undernutrition altered the response to maternal undernutrition in late gestation in apparent fetal plasma levels of IGFBP-1 analyzed by ligand blot analysis (Gallaher et al. 1995b).

Using specific RIAs for ovine IGFBP-3, IGFBP-2 and IGF-I, we examined in the present study whether adaptation to periconceptual undernutrition causes 1) persistent changes in either the fetal or maternal plasma IGF axis during late gestation, and/or 2) a reprogramming of the response of the fetal IGF axis to acute maternal undernutrition in late gestation. Such changes in homeostatic regulatory mechanisms could provide a potential link between aberrant fetal growth and associated pathophysiologies.

\section{Materials and Methods}

\section{Experimental design}

Coopworth-Border ewes were divided into two groups which were either fed ad libitum (AL) or undernourished (UN) for a period of 60 days prior to mating through until 30 days after conception (see Harding 1997 for experimental details). The undernutrition caused a $10 \%$ decrease in ewe body weight over the first 30 days which was then maintained for the subsequent 60 days. Between day 30 and 90 of gestation, both groups were allowed to feed ad libitum. Singleton-bearing ewes (AL, $n=9$; UN, $n=12$ ) were then brought into the laboratory and given a diet of concentrates and barley straw and allowed to feed ad libitum with free access to water. Ewes and their fetuses were chronically catheterized on day 95-100 of gestation (Oliver et al. 1992), allowed a 5-day recovery period and then each periconceptual nutrition group was further divided to receive either AL or UN diets for 10 days until day 115 of gestation, creating four treatment groups (AL-AL, $n=4$; AL-UN, $n=5$; UN-AL, $n=5$; UN-UN, $n=7$ ). During the late period of maternal undernutrition, feed intake was adjusted individually to maintain maternal preprandial blood glucose concentrations at $1.4-1.6 \mathrm{mM}$. Blood glucose concentrations in AL-fed ewes were approximately $2.5 \mathrm{mM}$. The maternal energy intake in the four different groups during the differential feeding period from day 105 to 115 of gestation was: AL-AL 15.2 $\pm 1 \cdot 7$; UN-AL $16 \cdot 5 \pm 2 \cdot 0, \quad$ AL-UN $\quad 0.6 \pm 0 \cdot 3, \quad$ UN-UN $0 \cdot 8 \pm 0 \cdot 5(\mathrm{MJ} /$ day). The detailed experimental procedures of this study have been described previously (Harding 1997). Fetal and maternal blood samples were collected at day 105 and 115 of gestation, placed on ice for no more than $15 \mathrm{~min}$, centrifuged at $3000 \mathrm{~g}$ for $15 \mathrm{~min}$ at $4{ }^{\circ} \mathrm{C}$ and the plasma stored at $-20^{\circ} \mathrm{C}$. These animal studies were approved by the University of Auckland Animal Ethics Committee.

\section{Measurements}

Ovine IGFBP-3 in fetal and maternal plasma was measured by a newly developed homologous oIGFBP-3 RIA described below. Immunoblots of oIGFBP-3 were performed using antiserum B12 (1:500 dilution) and an alkaline phosphatase detection system (Bio-Rad Laboratories, Richmond, CA, USA, see Gallagher et al. $1995 a$ for details). IGF-I and IGFBP-2 were measured by RIA as previously described (Breier et al. 1994, Gallagher et al. 1995a).

\section{oIGFBP-3 radioimmunoassay}

A semi-purified oIGFBP preparation from adult sheep serum was prepared following SP-Sephadex C25 extraction and IGF-II affinity chromatography (Gallagher et al. 1995a). The eluate was loaded onto a Pharmacia HR 5/10 C8 reverse phase column and proteins were eluted using a water-acetonitrile (ACN) gradient. Screening for oIGFBPs was performed by ligand blotting (Gallagher et al. 1992). Fractions containing oIGFBPs were separated using a Serva C18 reverse phase column using a $0 \cdot 1 \mathrm{M}$ triethylamine phosphate $\mathrm{pH} 3-\mathrm{ACN}$ gradient. Fractions containing the 39-42 kDa IGFBP doublet were used for raising antibodies, as assay standard or for N-terminal amino acid sequence analysis. Amino acid sequence analysis was performed using a gas-phase sequencer (740 A, Applied Biosystems, Foster City, CA, USA) equipped with an on-line PTH-amino acid analyser (120 A, Applied Biosystems) with chemicals and the program supplied by the manufacturer. The $15 \mathrm{~N}$-terminal amino acids of this protein (Table 1) showed strong homology with corresponding IGFBP-3 sequences from other species (Spratt et al. 1991).

Antisera against oIGFBP-3 were raised in New Zealand White rabbits following four immunizations with purified oIGFBP-3 $(25 \mu \mathrm{g})$ conjugated to keyhole limpet hemocyanin (Breier et al. 1991) in Freund's complete adjuvant. After immunoblotting with antiserum B12, a doublet of 39-42 kDa was seen with adult sheep plasma and purified oIGFBP-3 (Fig. 1). We detected additional low intensity bands at approximately $30 \mathrm{kDa}$ after extended exposure 
Table $1 \mathrm{~N}$-terminal amino acid sequence analysis (residues 1-15) of (a) purified ovine IGFBP-3 and (b-d) N-terminal sequences deduced from bovine, porcine and human IGFBP-3 cDNA (Spratt et al. 1991). Residues in bold indicate species-specific differences, in comparison with the purified ovine IGFBP-3.

\begin{tabular}{|c|c|c|c|c|c|c|c|c|c|c|c|c|c|c|}
\hline 1 & 2 & 3 & 4 & 5 & 6 & 7 & 8 & 9 & 10 & 11 & 12 & 13 & 14 & 15 \\
\hline Gly & Ala & Gly & Thr & Val & Gly & $\mathrm{Ala}$ & Gly & Pro & Val & Val & Arg & Cys & Glu & Pro \\
\hline Gly & Ala & Gly & Thr & Met & Gly & Ala & Gly & Pro & Val & Val & $\operatorname{Arg}$ & Cys & Glu & Pro \\
\hline Gly & Ser & Gly & Ala & Val & Gly & Thr & Gly & Pro & Val & Val & $\operatorname{Arg}$ & Cys & Glu & Pro \\
\hline Gly & Ala & Ser & Ser & Ala & Gly & Leu & Gly & Pro & Val & Val & $\operatorname{Arg}$ & Cys & Glu & Pro \\
\hline
\end{tabular}

which may indicate minor cross-reactivity with other IGFBPs or represent degraded or deglycosylated oIGFBP-3.

The ${ }^{125}$ I-oIGFBP-3 was prepared by iodinating $5 \mu \mathrm{g}$ purified oIGFBP-3 with $0.5 \mathrm{mCi}{ }^{125} \mathrm{I}$ using the chloramine-T method (Gallaher et al. 1995a) and purified by size separation chromatography. In the RIA, antiserum B12 gave $29 \%$ specific binding of ${ }^{125}$ I-oIGFBP-3 at a final dilution of 1:4500. Purified oIGFBP-3 for use as a standard and sheep plasma samples were diluted appropriately in assay buffer $(0.05 \mathrm{M}$ phosphate $\mathrm{pH} 7 \cdot 4,0 \cdot 1 \mathrm{M} \mathrm{NaCl}$, $0 \cdot 05 \% \mathrm{NaN}_{3}, 0 \cdot 1 \%$ Triton X-100, $\left.0 \cdot 2 \% \mathrm{BSA}\right)$. After pre-incubation of sample $(100 \mu \mathrm{l})$ with diluted antiserum (50 $\mu 1$ in assay buffer) and recombinant hIGF-I (batch G080AB R9821AX, Genentech Inc, San Francisco, CA, USA; $50 \mathrm{ng} / 50 \mu \mathrm{l}$ assay buffer) for $1 \mathrm{~h}$ at $20{ }^{\circ} \mathrm{C},{ }^{125} \mathrm{I}-$

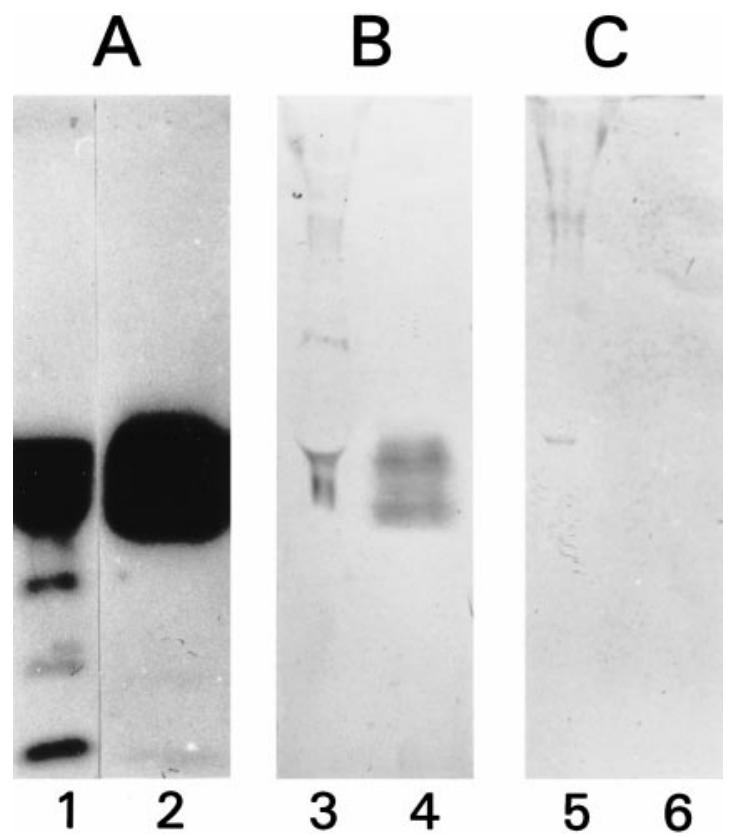

Figure 1 Specificity of antiserum B12 for olGFBP-3-screening of adult sheep plasma (lanes 1, 3 and 5) and purified olGFBP-3 (lanes 2, 4 and 6) using (A) ligand or Western blot with (B) antiserum B12 and (C) non-immune serum.
oIGFBP-3 (20 000 c.p.m. in $100 \mu \mathrm{l}$ assay buffer) was added and the assay incubated overnight at $4{ }^{\circ} \mathrm{C}$. Recombinant hIGF-I was added to correct the potency difference for the antiserum between free oIGFBP-3 (tracer and standard curve) and IGF-associated oIGFBP-3 in the plasma samples. Second antibody solution (1 $\mathrm{ml} 0 \cdot 5 \%$ sheep $\alpha$-rabbit $\gamma$ globulin antiserum, $0 \cdot 1 \%$ normal rabbit serum, 5\% PEG 6000 in 0.01 M PBS pH 7.4) was added to each tube and the assay was incubated for $1 \mathrm{~h}$ at $20^{\circ} \mathrm{C}$ before centrifuging at $3000 \mathrm{~g}$ for $30 \mathrm{~min}$ at $4{ }^{\circ} \mathrm{C}$. The pellets were counted by gamma counter.

The homologous oIGFBP-3 RIA exhibited parallel displacement between purified oIGFBP-3 and sheep plasma. The $\mathrm{ED}_{50}$ for the assay was $1.5 \mathrm{ng}$ oIGFBP-3/ tube and the minimal detectable dose was $5 \mathrm{ng} / \mathrm{ml}$. The intra- and interassay coefficients of variation were 6 and $12 \%$ respectively. There was no significant cross-reactivity with human, porcine or rat serum but strong crossreactivity with bovine serum (Fig. 2). Further addition of

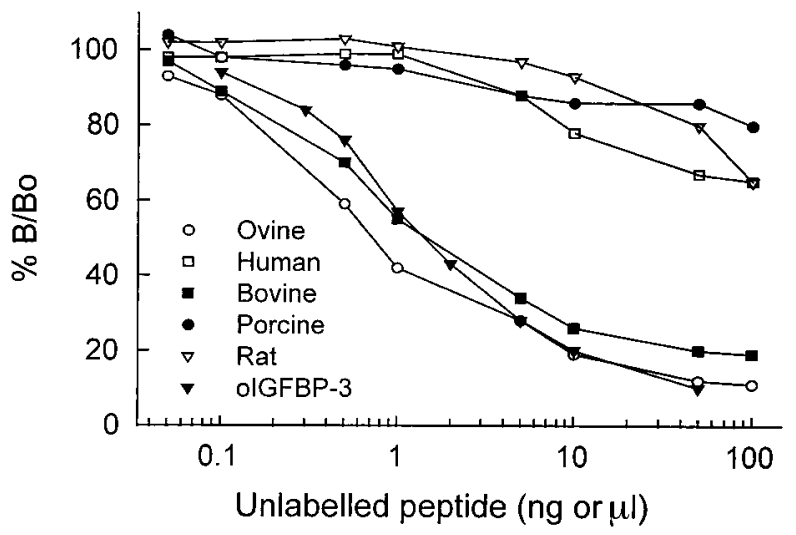

Figure 2 The olGFBP-3 RIA was assessed for sensitivity and parallelism of ovine plasma relative to purified olGFBP-3 and cross-reactivity with plasma from other species. The displacement curves are as follows: purified olGFBP-3 $\boldsymbol{\nabla}$, ovine plasma $\bigcirc$, human plasma $\square$, bovine plasma $\mathbf{\square}$, rat plasma $\nabla$, porcine plasma $\bullet$. Each point is the mean of duplicates expressed as percentage bound (\% B/Bo) corrected for non-specific binding. Buffer-diluted plasma volumes are expressed in terms of neat plasma volume equivalents. 
Table 2 Analysis of interference by IGF-I, IGF-II and heparin in the ovine IGFBP-3 assay. Serum control pools ( $n=4$; range: $500-$ $2500 \mathrm{ng} / \mathrm{ml}$ IGFBP-3) were assayed with increasing amounts of unlabelled IGF-I or IGF-II. Blood with and without heparin was also collected $(n=2)$. Recoveries are expressed as percentage of relative values to the unspiked sample (means \pm S.E.M.).

\begin{tabular}{|c|c|c|c|}
\hline & $\begin{array}{l}\text { Recovery } \\
(\%)\end{array}$ & GFBP-3 & \\
\hline & IGF-I & IGF-II & Heparin \\
\hline Amount ad & & & \\
\hline $100 \mathrm{ng} / \mathrm{ml}$ & $98 \pm 2$ & $97 \pm 4$ & - \\
\hline $250 \mathrm{ng} / \mathrm{ml}$ & $96 \pm 5$ & $101 \pm 4$ & - \\
\hline $750 \mathrm{ng} / \mathrm{ml}$ & $100 \pm 3$ & $105 \pm 2$ & - \\
\hline $25 \mathrm{IU} / \mathrm{ml}$ & - & - & $102 \pm 5$ \\
\hline
\end{tabular}

IGF-I, IGF-II or heparin to control sheep plasma samples did not affect the values obtained (Table 2).

\section{Statistical analysis}

Differences between day 105 and 115 of gestation and between the treatment groups for IGFBP-2, IGFBP-3 and IGF-I were analyzed by two way repeated measures ANOVA followed by Neuman-Keuls post-hoc test (Sigmastat, Jandel Scientific, Chicago, IL, USA). IGFBP-3 and IGF-I values for each animal on day 115 of gestation were also expressed as a ratio over the corresponding day 105 value to eliminate the effect of baseline variation at day 105 of gestation. Changes in peptide concentrations between day 105 and 115 of gestation were then analyzed for inter-group differences by one way ANOVA followed by Scheffe's test (Sigmastat, Jandel Scientific). Statistical significance was accepted at $P<0 \cdot 05$. Data are expressed as means \pm S.E.M.

\section{Results}

Plasma concentrations of IGF-I did not differ at day 105 of gestation between fetuses or mothers of the four treatment groups (Fig. 3). However, there was a significant reduction in fetal and maternal plasma IGF-I at day 115 of gestation, as a result of maternal undernutrition in late gestation. The fall in fetal plasma IGF-I between day 105 and 115 of gestation was also significantly greater in the group undernourished at the time of conception (AL-UN $31 \pm 6 \%$; UN-UN $54 \pm 6 \%, P<0 \cdot 05)$. Fetal and maternal plasma IGFBP-3 concentrations (Fig. 4) were not different between groups at day 105. At day 115 of gestation, maternal and fetal plasma concentrations of IGFBP-3 were similar in the AL-fed groups (AL-AL; UN-AL) but fell in the UN-fed groups between day 105 and 115 of gestation (AL-UN; UN-UN). The fall in fetal plasma IGFBP-3 concentrations was greater in the UN-UN group than that

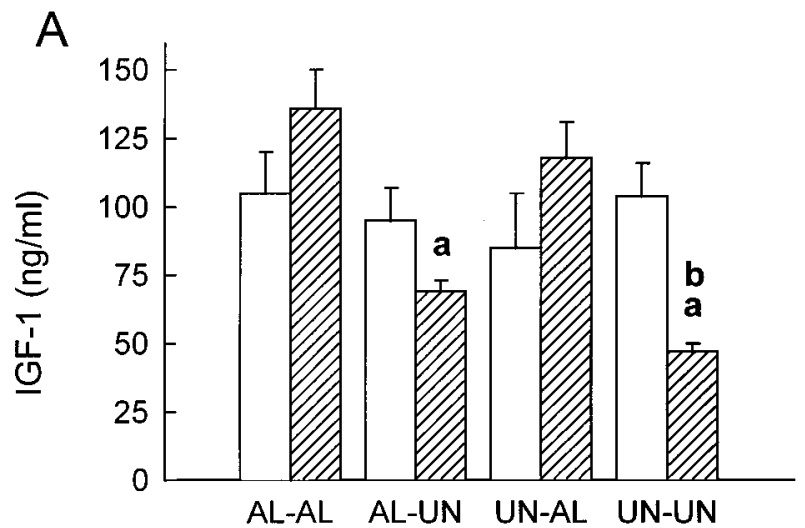

B

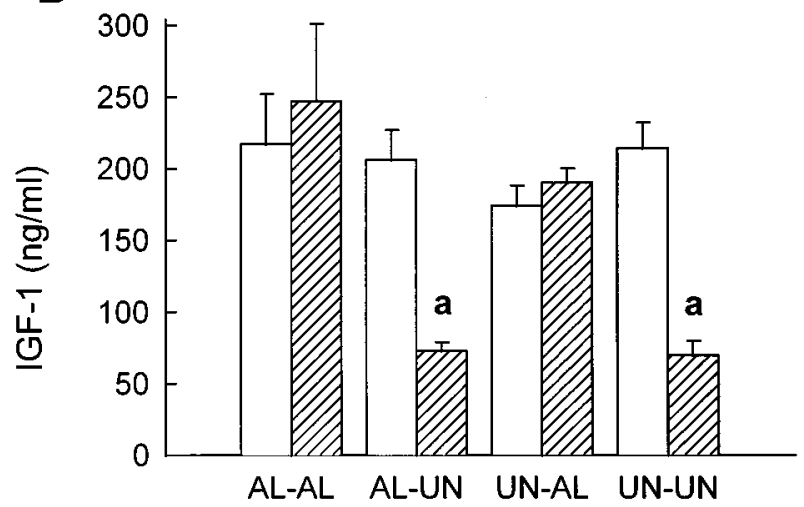

Figure 3 Plasma levels of (A) fetal IGF-I and (B) maternal IGF-I at day 105 (open bars) and at day 115 of gestation (hatched bars). Values (means \pm S.E.M.) are IGF-I concentrations $(\mathrm{ng} / \mathrm{ml})$. See text for description of groups. ${ }^{a} P<0.05$ day 105 vs day 115 within groups; ${ }^{b} P<0.05$ comparing \% change (day 105-115) with AL-UN group.

in the AL-UN group (UN-UN $63 \pm 2 \%$; AL-UN $28 \pm 13 \%, P<0 \cdot 05)$. Manipulation of maternal nutrition had no effect on fetal IGFBP-2 levels (values in $\mathrm{ng} / \mathrm{ml}$ : AL-AL day $105449 \pm 76$, day $115425 \pm 35$; AL-UN day $105415 \pm 27$, day $115458 \pm 22$; UN-AL day 105 $427 \pm 24$, day $115501 \pm 50 ;$ UN-UN day $105496 \pm 29$, day $115474 \pm 39)$.

Fetal and maternal plasma samples were also examined by Western blotting to examine the presence of IGFBP-3 proteolysis which had been demonstrated in other species in the maternal circulation during late gestation and in postnatal catabolic states. There was little evidence of bands of smaller size than the 39-42 kDa doublet of intact oIGFBP-3 in maternal or fetal samples at either timepoint (Fig. 5). Our data suggest that IGFBP-3 proteases appear to be absent from late gestation maternal or fetal sheep plasma and that the reductions in plasma IGFBP-3 as measured by RIA in the mothers and their fetuses as a response to undernutrition are not due to proteolytic cleavage of this binding protein. 


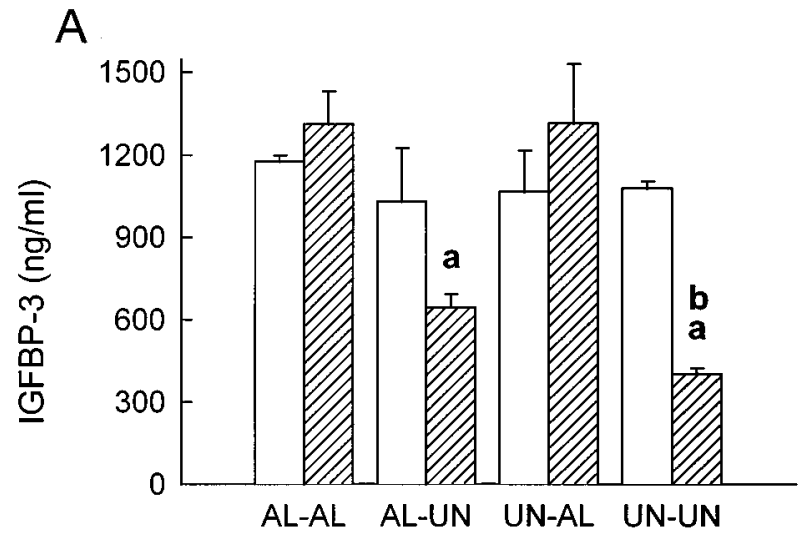

B

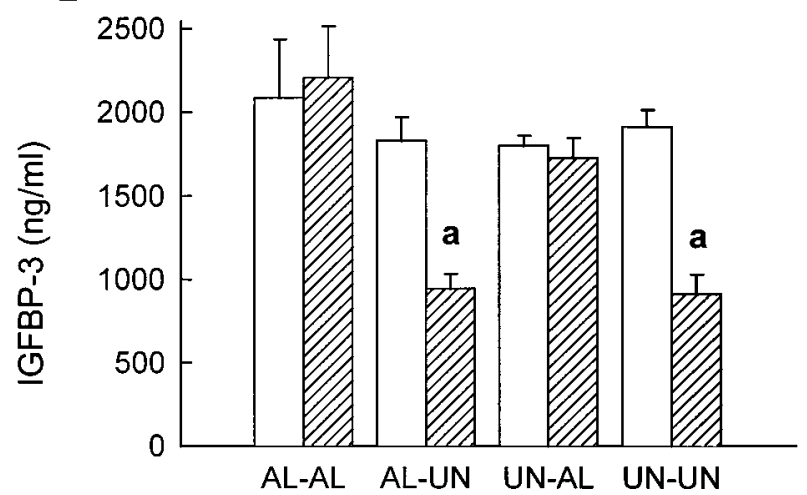

Figure 4 Plasma levels of (A) fetal ovine IGFBP-3 or (B) maternal ovine IGFBP-3 at day 105 (open bars) and at day 115 of gestation (hatched bars). Values (means \pm S.E.M.) are IGFBP-3 concentrations $(\mathrm{ng} / \mathrm{ml})$. See text for description of groups. ${ }^{\mathrm{a}} \mathrm{P}<0 \cdot 05$ day $105 \mathrm{vs}$ day 115 within group; ${ }^{b} P<0.05$ comparing $\%$ change (day 105-115) with AL-UN group.

\section{Discussion}

This paper reports an alteration in regulation of the IGF-I and IGFBP-3 in the developing fetal sheep following exposure of the mother to periconceptual undernutrition. While basal IGF-I and IGFBP-3 concentrations in both maternal and fetal sheep plasma during late gestation were not altered, periconceptual undernutrition of the ewe amplified the reduction of IGF-I and IGFBP-3 in fetal plasma in response to 10 days of maternal undernutrition in late gestation. Our results therefore suggest that periconceptual undernutrition may reprogram (persistently alter the normal developmental pattern and homeostatic regulatory mechanisms) the fetal IGF-I and IGFBP-3 system in its ability to respond to acute changes in substrate supply. This reprogramming of IGF-I and IGFBP-3 during fetal development may be of particular physiologic significance for the long-term regulation of fuel homeostasis, since the fetal response to late gestation maternal undernutrition in plasma glucose and insulin was not altered by periconceptual maternal undernutrition (Gallagher et al. 1995b).

Whether other members of the IGF axis in the fetal sheep are similarly reprogrammed by maternal periconceptual undernutrition awaits further investigations. We found no evidence for long-term consequences of periconceptual maternal undernutrition on fetal plasma concentrations of IGFBP-2 (present study). However, preliminary data from this laboratory (Gallagher et al. 1995b) using ligand blot analysis, would suggest that the increase in fetal plasma IGFBP-1 as a response to acute maternal undernutrition in late gestation may similarly be altered by reprogramming during early fetal life (Gallagher et al. 1995b).

The physiologic significance of reprogramming of fetal IGF-I and IGFBP-3 is not clearly defined at present. Harding (1997) measured fetal growth rates in vivo in the first part of this study using growth-measuring devices, which had been surgically placed at day 95 of gestation. Her study showed that maternal undernutrition from 60 days before until 30 days after conception resulted in fetuses with relatively slow growth between day 98 and 105. Undernutrition in late gestation (day 105-115) markedly reduced fetal growth rate in the AL-UN group, but did not change the already slow growth in the UN-UN group. This slower rate of fetal growth in the UN-UN group during late pregnancy appeared to partially protect the fetus against further reduction in growth and against a relative increase in heart, kidney and liver size caused by 10 days of severe maternal undernutrition in late gestation (Harding 1997). It is therefore tempting to speculate that the amplified reduction in fetal plasma IGF-I and IGFBP-3 during late gestation maternal undernutrition (in the UN-UN group at day 115) may be an adaptive mechanism of the reprogrammed fetal somatotropic axis which partly protects the fetus against a further slowing of growth and a relative over-growth of the heart, kidney and liver. The amplified reduction in fetal plasma IGF-I and IGFBP-3 in response to acute maternal undernutrition in late gestation in the UN-UN group may reflect alterations in hepatic synthesis or clearance induced by maternal periconceptual undernutrition.

Reprogramming of postnatal endocrine parameters as a result of endocrine manipulations during fetal development has already been described. For example, passive immunization of the fetal rat against growth hormone (GH)-releasing hormone permanently alters adult GH secretion (Cella et al. 1994). Muaku et al. (1996) showed in the rat that offspring from mothers fed on a low protein diet throughout gestation are growth retarded at birth and have reduced plasma levels of IGF-I postnatally until they reach puberty. Our own studies in the rat showed significant growth retardation at birth and reduced postnatal growth and plasma concentrations of IGF-I in offspring of mothers given a nutritionally-balanced diet and allowed to feed just 30\% ad libitum (Woodall et al. 1996a). However, 
A

AL-AL AL-UN UN-AL UN-UN

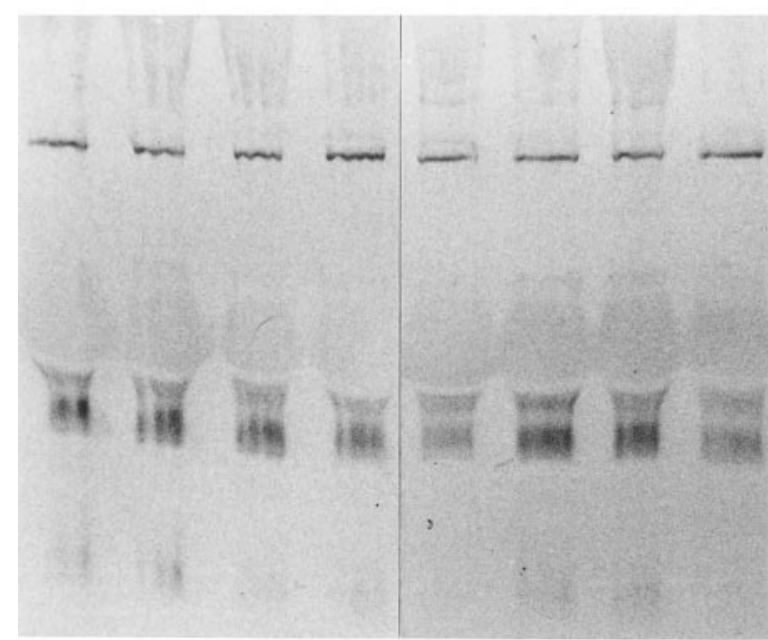

$\begin{array}{llllllll}1 & 2 & 3 & 4 & 5 & 6 & 7 & 8\end{array}$
B

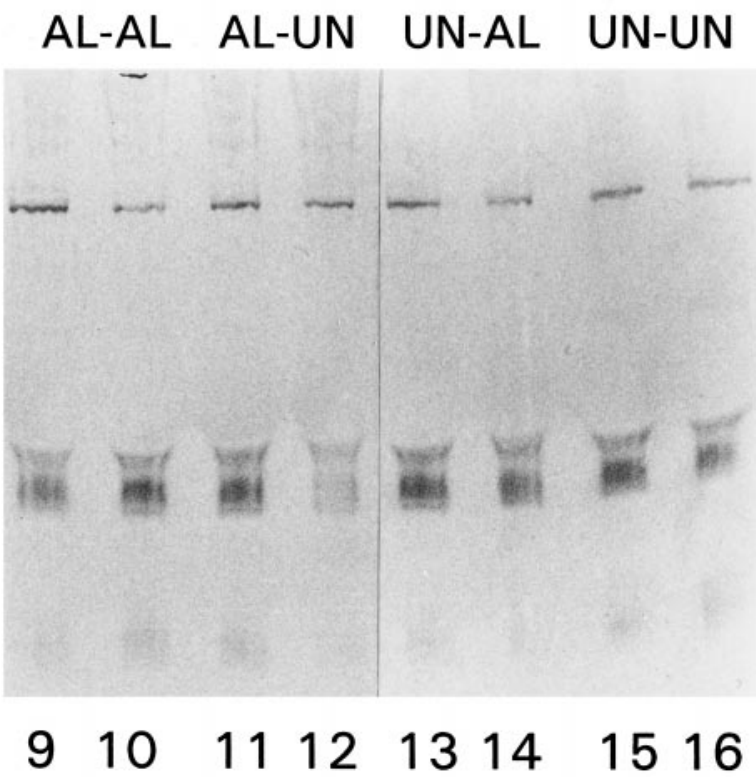

Figure 5 Representative olGFBP-3 Western blots of (A) fetal and (B) maternal plasma from each group (see text for description) at day 105 (odd-numbered lanes) and day 115 (even-numbered lanes) of gestation.

in this model of fetal growth retardation plasma IGF-I concentrations had recovered at weaning, but we observed significant hypertension during adult life (Woodall et al. 1996b).

The present study provides the first example of reprogramming of the somatotropic axis during fetal life caused by manipulation of maternal nutrition. A related phenomenon has been previously suggested in fetal sheep. The effect of maternal starvation in late gestation on ovine placental lactogen (oPL) concentrations in fetal plasma differs depending on the level of maternal nutrition immediately prior to starvation (Oliver et al. 1992). The mechanisms responsible for the amplified reduction of fetal plasma IGF-I and IGFBP-3 in response to the maternal undernutrition in late gestation in the UN-UN group are unclear. One possible explanation may relate to the effects of periconceptual undernutrition on fetal responsiveness to corticosteroids in late gestation. Although we did not measure cortisol in this study, it is known that maternal undernutrition can elevate cortisol in the late-gestation fetal sheep (Binienda et al. 1990) and that cortisol exposure can increase blood pressure (Tangalakis et al. 1992) in the fetal sheep. Blood pressure was elevated in fetuses of our study (Harding \& Johnston 1995). Corticosteroid-induced growth retardation of the fetal rat also lowers IGFBP-3 expression and plasma IGF-I (Zhou-Li et al. 1991, Price et al. 1992). The cortisol secretory response to hypoxemia decreases with advancing gestational age (Akagi \& Challis 1990). Any delay in this maturation process caused by exposure to periconceptual undernutrition could then lead to a greater fetal cortisol response to undernutrition in late gestation and therefore a greater decrease in IGF-I and IGFBP-3 seen in the UN-UN group. Whether altered plasma cortisol levels are causally related to reprogramming of the fetal IGF axis awaits further investigations.

This paper also reports the development of a homologous RIA for oIGFBP-3 and its use in examining the effects of periconceptual undernutrition on the maternal and fetal IGF axes in the late gestation sheep. The oIGFBP-3 39-42 kDa doublet, purified from adult sheep serum by IGF-II affinity chromatography and reverse phase chromatography, showed significant $\mathrm{N}$-terminal sequence homology with equivalent cDNA-derived sequences for bovine, porcine and human IGFBP-3 (Spratt et al. 1991). The antiserum raised against this protein was specific for oIGFBP-3. Both fetal and postnatal plasma samples exhibited parallel displacement to purified oIGFBP-3 in the RIA with no interference from IGFs or heparin.

Of interest is the observation that, when analyzed by specific RIA, IGFBP-3 concentrations were not suppressed in day 105 fetal plasma in groups whose mothers received periconceptual undernutrition, in contrast to the results of earlier studies from this laboratory using ligand blotting where apparent IGFBP-3 values were reduced at day 105 in the UN-AL and UN-UN groups (Gallagher et al. 1995b). This discrepancy reinforces previous debate indicating that ligand blot and immunologically based 
analyses can produce disparate results (Gargosky et al. 1992), reflecting the different properties on which the methodology is based, either immunoreactive peptide or IGF binding activity. A functional difference such as reduced affinity for the IGFs by IGFBP-3 in fetuses from the periconceptual undernutrition groups (UN-AL, UN-UN) may explain the apparent suppression of IGFBP-3 on ligand blots at day 105 gestation. While this could potentially be achieved by the induction of IGFBP-3 protease activity following periconceptual maternal undernutrition, our Western blotting analysis revealed minimal levels of low molecular weight immunoreactive IGFBP-3 in all experimental groups at day 105 gestation, implying that IGFBP-3 is intact and of normal size in fetal sheep plasma. IGFBP-3 protease activity is also not clearly demonstrable in mid-to-late gestation fetal plasma of some other species (Lewitt et al. 1995). The lack of degradation products at day 115 in fetal plasma following severe undernutrition also suggests that induction of IGFBP-3 protease activity is not responsible for the greater fall in immunoreactive IGFBP-3 plasma levels in the UN-UN fetuses. Further analysis using IGFBP-3 proteolysis assays would confirm this observation.

We were not able to demonstrate any changes in responsiveness to late gestation undernutrition in maternal plasma IGF-I and IGFBP-3. However, we did note in Western blots that IGFBP-3 in late gestation maternal sheep plasma was essentially intact which is in contrast to other species such as man and rodents (Lewitt et al. 1995) where little IGFBP-3 is intact at this stage of pregnancy. Such species specific differences could reflect differences in placental structure between these species. Since maternal plasma IGF-I is a key element in enhancing placental function in the sheep (Liu et al. 1994), the ewe is likely to have alternative means of increasing IGF-I availability to the placenta.

Several postnatal endocrine consequences have already been ascribed to the effects of growth retardation in utero. Humans who are born small exhibit an altered glucose metabolism such that, as adults, they have an increased risk of developing non-insulin dependent diabetes (Hales et al. 1991). Rats, growth retarded in utero, were unresponsive to $\mathrm{GH}$ treatment between day 11 and 21 postnatally but not after puberty, suggesting the presence of transient GH resistance during the neonatal period due to the intrauterine growth retardation (Woodall et al. 1997). The postnatal consequences of changes in the fetal IGF axis described in this study are not known but they do support the hypothesis that nutritional reprogramming of the fetal IGF axis during early gestation might establish altered homeostatic patterns to subsequent nutritional limitation which could then contribute to postnatal pathophysiology. Further studies are clearly required to examine any postulated changes in postnatal growth and/or the development of the somatotropic axis in offspring of mothers who experienced major nutritional restriction during the periconceptual period.

\section{Acknowledgements}

This work was supported by the Health Research Council of New Zealand and the National Child Health Research Foundation. The authors thank Dr David Christie, School of Biological Sciences, University of Auckland, for performing the oIGFBP-3 N-terminal amino acid sequence analysis.

\section{References}

Akagi K \& Challis JR 1990 Threshold of hormonal and biophysical responses to acute hypoxemia in fetal sheep at different gestational ages. Canadian Journal of Physiology and Pharmacology 68 549-555.

Baker J, Liu J, Robertson EJ \& Efstratiadis A 1993 Role of insulin-like growth factors in embryonic and postnatal growth. Cell 75 73-82.

Barker DJP 1997 Fetal undernutrition and adult disease. Endocrinology and Metabolism 4 (Suppl. B) 39-46.

Barker DJP, Gluckman PD, Godfrey KM, Harding JE, Owens JA \& Robinson JS 1993 Fetal nutrition and cardiovascular disease in adult life. Lancet 341 938-941.

Barker DJP, Gluckman PD \& Robinson JS 1995 Conference report: fetal origins of adult disease: report of the First International Study Group, Sydney, 29-30 October 1994. Placenta 16 317-320.

Binienda Z, Rosen ED, Kelleman A, Sadowsky DW, Nathanielsz PW \& Mitchell MD 1990 Maintaining fetal normoglycemia prevents the increase in myometrial activity and uterine 13,14-dihydro-15keto-prostaglandin F2 alpha production during food withdrawal in late pregnancy in the ewe. Endocrinology 127 3047-3051.

Breier BH, Gallaher BW \& Gluckman PD 1991 Radioimmunoassay for insulin-like growth factor-I: solutions to some potential problems and pitfalls. Journal of Endocrinology 128 347-357.

Breier BH, Ambler GR, Sauerwein H, Surus A \& Gluckman PD 1994 The induction of hepatic somatotrophic receptors after birth in sheep is dependent on parturition associated mechanisms. Journal of Endocrinology 141 101-108.

Cella SG, Locatelli V, Broccia ML, Meregola E, Giavini E, De Gennaro Colonna V, Torsello A, Wehrenberg WB \& Muler EE 1994 Long term changes in somatotrophic function induced by deprivation of growth hormone releasing hormone during the fetal life of the rat. Journal of Endocrinology 140 111-117.

Gallaher BW, Breier BH, Oliver MH, Harding JE \& Gluckman PD 1992 Ontogenic differences in the nutritional regulation of circulating IGF binding proteins in sheep plasma. Acta Endocrinologica 126 49-54.

Gallaher BW, Oliver MH, Eichhorn K, Kessler U, Kiess W, Harding JE, Gluckman PD \& Breier BH 1994 The circulating IGF-II/mannose-6-phosphate receptor and insulin-like growth factor binding proteins in fetal sheep plasma are regulated by glucose and insulin. European Journal of Endocrinology 131 398-404.

Gallaher BW, Breier BH, Blum WF, McCutcheon SN \& Gluckman PD 1995a An homologous radioimmunoassay for ovine insulin-like growth factor binding protein 2 (oIGFBP-2): ontogenesis and the response to growth hormone, placental lactogen and IGF-I treatment. Journal of Endocrinology 144 75-82.

Gallaher BW, Breier BH, Harding JE \& Gluckman PD 1995 b Periconceptual undernutrition resets plasma IGFBP levels and alters the response of IGFBP-1, IGFBP-3 and IGF-I to subsequent maternal undernutrition in the sheep. Progress in Growth Factor Research 6 189-195. 
Gargosky SE, Pham HM, Wilson KF, Liu F, Giudice LC \& Rosenfeld RG 1992 Measurement and characterization of insulin-like growth factor binding protein-3 in human biological fluids: discrepancies between radioimmunoassay and ligand blotting. Endocrinology 131 3051-3060.

Gluckman PD 1995 The endocrine regulation of fetal growth in late gestation: the role of insulin-like growth factors. Journal of Clincal Endocrinology and Metabolism 80 1047-1050.

Hales CN, Barker DJ, Clark PM, Cox LJ, Fall C, Osmond C \& Winter PD 1991 Fetal and infant growth and impaired glucose tolerance at age 64. British Medical Journal 303 1019-1022.

Han VKM, Asano H, Matsell DG, Debhumty PJD, Hayatsu J, Bassett N, Phillips ID, Nygard K \& Stepaniuk O 1994 Insulin-like growth factors (IGFs) and IGF binding protein (IGFBPs) in fetal development: physiology and pathophysiology. In The Insulin-like Growth Factors and their Regulatory Proteins, pp 263-273. Eds RC Baxter, PD Gluckman \& RG Rosenfeld. Amsterdam: Elsevier.

Harding JE 1997 Periconceptual nutrition determines the fetal growth response to acute maternal undernutrition in fetal sheep of late gestation. Prenatal and Neonatal Medicine 2 310-319.

Harding JE \& Johnston BM 1995 Nutrition and fetal growth. Reproduction, Fertility and Development 7 539-547.

Lewitt MS, Scott FP, Clarke NM \& Baxter RC 1995 Developmental regulation of circulating insulin-like growth factor binding proteins in normal pregnancies and in pre-eclampsia. Progress in Growth Factor Research 6 475-480.

Liu L, Harding JE, Evans PC \& Gluckman PD 1994 Maternal insulin-like growth factor-I infusion alters feto-placental carbohydrate and protein metabolism in pregnant sheep. Endocrinology 135 895-900.

Mellor DJ \& Matheson IC 1979 Daily changes in the curved crown-rump length of individual sheep fetuses during the last 60 days of pregnancy and effects of different levels of maternal nutrition. Quarterly Journal of Experimental Physiology 64 119-131.

Muaku SM, Beauloye V, Thissen JP, Underwood LE, Fossion C, Gerard G, Ketelslegers JM \& Maiter D 1996 Long-term effects of gestational protein malnutrition on postnatal growth, insulin-like growth factor (IGF)-I, and IGF-binding proteins in rat progeny. Pediatric Research 39 649-655.

Oliver MH, Harding JE, Breier BH, Evans PC \& Gluckman PD 1992 The nutritional regulation of circulating placental lactogen in fetal sheep. Pediatric Research 31 520-523.

Osborn BH, Fowlkes J, Han VKM \& Freemark M 1992 Nutritional regulation of insulin-like growth factor-binding protein gene expression in the ovine fetus and the pregnant ewe. Endocrinology 131 1743-1750.

Owens JA, Falconer J \& Robinson JS 1987 Effect of restriction of placental growth on fetal and utero-placental metabolism. Journal of Developmental Physiology 9 225-238.

Persson E \& Jansson T 1992 Low birth weight is associated with elevated adult blood pressure in the chronically catheterised guinea pig. Acta Physiologica Scandinavica 145 195-196.

Price WA, Stiles AD, Moats-Staats BM \& D’Ercole AJ 1992 Gene expression of insulin-like growth factors (IGFs), the type I IGF receptor, and IGF-binding proteins in dexamethasone-induced fetal growth retardation. Endocrinology 130 1424-1432.

Strauss DS, Ooi GT, Orlowski CC \& Rechler MM 1991 Expressions of the genes for IGF-I, IGF-II and IGFBP-1 and -2 in the fetal rat under conditions of intra-uterine growth retardation caused by maternal fasting. Endocrinology 128 518-525.

Spratt SK, Tatsuno GP \& Sommer A 1991 Cloning and characterization of bovine insulin-like growth factor binding protein-3 (bIGFBP-3). Biochemical and Biophysical Research Communications 177 1025-1032.

Tangalakis K, Lumbers ER, Moritz KM, Towstoless MK \& Wintour EM 1992 Effect of cortisol on blood pressure and vascular reactivity in the ovine fetus. Experimental Physiology 77 709-717.

Woodall SM, Breier BH, Johnston BM \& Gluckman PD 1996a A model of intrauterine growth retardation caused by chronic maternal undernutrition in the rat: effects on the somatotrophic axis and postnatal growth. Journal of Endocrinology 150 231-242.

Woodall SM, Johnston BM, Breier BH \& Gluckman PD 1996 b Chronic maternal undernutrition in the rat leads to delayed postnatal growth and elevated blood pressure of offspring. Pediatric Research 40 438-443.

Woodall SM, Breier BH, Johnston BM \& Gluckman PD 1997 Reduced maternal nutrition during gestation in the rat leads to temporary growth hormone resistance during the neonatal period. Proceedings of the 79th Annual Meeting of the Endocrine Society P1.123.

Zhou-Li F, Joly-Pharaboz MO, Bouillard B, Albaladejo V, Nicolas B \& Andre J 1991 Multihormonal control of cell proliferation: opposite effects of two stimulators (17 beta-estradiol and L-triiodothyronine) and one inhibitor (dexamethasone) on F4Z2 pituitary tumor cells. Endocrinology 128 2761-2768.

Received 9 December 1997

Accepted 8 July 1998 